\title{
Sosok Perempuan dalam Pandangan Bung Karno pada Memoar Sarinah: Sebuah Analisis Wacana Kritis Feminis
}

\author{
Suyanto \\ Fakultas Ilmu Budaya, Universitas Diponegoro \\ suyanto@live.undip.ac.id
}

\begin{abstract}
This study aims: (1) to describe and explain Soekarno's views about women in Sarinah's memoir by Ir. Soekarno and (2) explained the portrait of Sarinah, a woman during the independence period. Both of these aspects are explained in the frame of sociocultural factors that cause sexism in Sarinah's memoirs. The material object of this research is a memoir entitled Sarinah, by Ir. Soekarno, first President of the Republic of Indonesia. The formal object of this research is the use of Indonesian in the perspective of critical feminist discourse analysis in the Sara Mills Model. Data collection is done by referring to the method developed with note-taking techniques and literature studies to capture data on social identity, knowledge, and author's beliefs and literature to obtain data on the social, institutional, and situation of the birth of the memoir. Data analysis is done by reducing data, displaying data, verifying data, interpreting and interpreting the theory, and summarizing the results. In analyzing the data of this study, it was explained by Sara Mills's feminist stylistic theory and Teun van Dijk's social cognition theory.

Keywords: Language usage; language sexism; Sarinah; Ir. Soekarno; Sarinah figure.
\end{abstract}

\section{Intisari}

Penelitian ini bertujuan: (1) mendeskripsikan dan menjelaskan pandangan Soekarno tentang perempuan dalam memoar Sarinah karya Ir. Soekarno dan (2) menjelaskan potret Sarinah, perempuan pada masa kemerdekaan. Kedua aspek tersebut dijelaskan dalam bingkai faktor-faktor sosiokultural yang menyebabkan seksisme dalam memoar Sarinah. Objek material penelitian ini adalah memoar berjudul Sarinah, karya Ir. Soekarno, Presiden RI pertama. Objek formal penelitian ini adalah pemakaian bahasa Indonesia dalam perspektif analisis wacana kritis feminis Model Sara Mills. Pengumpulan data dilakukan dengan metode simak yang dikembangkan dengan teknik catat dan studi pustaka untuk menjaring data identitas sosial, pengetahuan, dan keyakinan penulis dan penelusuran pustaka untuk mendapatkan data konteks sosial, institusi, dan situasi lahirnya memoar tersebut. Analisis data dilakukan dengan reduksi data, displai data, verifikasi data, penafsiran dan pemaknaan teoretik, dan penyimpulan hasil. Dalam analisis data studi ini, dijelaskan dengan teori stilistika feminis Sara Mills dan teori kognisi sosial Teun van Dijk.

Kata kunci:Pemakaian bahasa; seksisme bahasa; Sarinah; Ir.Soekarno; sosok Sarinah. 


\section{Pendahuluan}

Sebuah karya, baik memoar maupun karya sastra merupakan cermin kondisi kehidupan sosial budaya di mana dan kapan karya itu diciptakan dan pandangan tentang penulis tentang suatu hal, termasuk di dalamnya fenomena terkait dengan jender. Ketika lingkungan sosial dan budaya penuh praktik hegemoni suatu kelompok atas kelompok yang lain, termasuk didalamnya hegemoni jender, laki-laki atas perempuan, maka hal itu akan terekam dalam karya yang diciptakan tersebut. Demikian juga ketika ketidakadilan jender merasuk pada semua aspek dan lini kehidupan, maka hal semacam itu juga akan terepresentasi dalam karya seseoran termasuk di dalamnya memaoar atau karya sastranya (Astuti, 2002; Sunardi, 2007;Nurulhadi, 2011; Sungkar, 2011). Sebuah karya memoar atau karya sastra sebagai potret kehidupan zamannya, diungkapan menggunakan media bahasa, dalam hal ini bahasa Indonesia. Dalam karya memoar atau sastra melalui bahasa yang dipergunaannya telah ditunjukkan sosok perempuan dan relasi jender, baik berupa karakter, profesi, kedudukan, maupun pengorbanan hidup yang dilakukan oleh perempuan. Dalam studi karya sastra, melalui bahasa yang dipergunakan telah terbukti mengukuhkan stereotip perempuan yang harus hidup dan tunduk pada sistem patriarki (Muzakka, 2011). Akan tetapi, perlu sebuah studi spesifik tentang memoar seorang tokoh besar untuk mengetahui dan menjelaskan bagaimana penulis mempersepsikan perempuan. Persepsi penulis merupakan kombinasi dari pandangan saat itu, pandangan laki-laki, dan tradisi waktu tersebut dalam memperlakukan perempuan. Sampai saat ini, menurut studi intensif yang penulis lakukan ternyata belum pernah dilakukan kajian spesifik tentang jender terhadap buku memoar. Memoar yang menjadi fokus studi ini adalah karya Ir. Soekarno, Presiden pertama Republik Indonesia yang berjudul Sarinah: Kewajiban Wanita dalam Perjoangan Republik Indonesia (selanjutnya disingkat Sarinah).

Dalam penelitian ini, memoar Sarinah dianalisis menggunakan teori wacana stilistika feminis (feminist stylistics ) Sara Mills (1995). Ancangan ini dipilih karena dalam analisis tidak hanya memfokuskan pada tataran bentuk teks (ciri-ciri linguistik), tetapi juga menjelaskan di balik bentuk tersebut, yakni praktik komunikasi atau tindak bahasa, dan praktik sosial. Hal tersebut dilakukan dengan cara mendeskripsikan dan menjelaskan bagaimana seksisme ditampilkan dalam tataran wacana, serta mengelaborasikannya dengan identitas sosial dan faktor sosiokultural penulis. 
Abbas Deygan Darweesh dan Hussein Huwail Gayadh (2016) telah melakukan penelitian yang mengungkapkan hubungan ideologi dan kekuatan dalam berbagai tingkatan, yaitu kata, frasa atau kalimat, dan wacana. Sementara itu, Budiwati dan Wijana (2004) menganalisis tingkat bias jender antar-etnis. Penutur bahasa Indonesia yang beretnis Jawa dan non Jawa menunjukkan tingkat bias jender yang berbeda dalam pemakaian peristilahan berhubungan dengan aspek jender dalam bahasa Indonesi (Budiwati dan Wijana, 2004).

Penelitian-penelitian di atas menunjukan keterkaitan bahasa dan gender serta pengaruhnya satu sama lain. Hal ini membenarkan secara langsung pendapat Graddol dan Swann (1989: 12-16) yang telah merangkum hubungan antara bahasa dengan jender, yaitu 1) bahasa mencerminkan pembagian sosial dan ketidaksetaraan; 2) pembagian dan kesetaraan tersebut diciptakan oleh prilaku bahasa yang seksis; 3) kedua proses tersebut saling mempengaruhi, dan setiap bahasa dan jender harus menyelidiki keterkaitan di antara keduanya.

Stilistika feminis merupakan analisis wacana kritis yang melibatkan topik stilistika (gaya bahasa) dan gender. Teori ini dikembangkan oleh Sara Mills (1995). Analisis wacana yang dikembangkan oleh Sara Mills terbagi pada tiga tataran analisis, yaitu analisis pada tataran kata, kalimat, dan wacana, namun studi ini hanya focus pada tataran wacana.

Analisis tataran wacana merupakan analisis secara keseluruhan yang mencakup 4 bagian. Pertama, analisis karakterisasi atau peran yang menyelidiki konstruksi jender pada setiap peran. Kedua, analisis fragmentasi yang membahas bagaimana perempuan direpresentasikan dan bentuk fragmentasi yang terjadi dalam teks. Ketiga, fokalisasi yang mendeskripsikan sudut pandang teks. Yang terakhir, skemata yaitu analisis alur atau skema teks untuk mengetahui pola dominan dalam menarasikan jender.

\section{Metode Penelitian}

Penelitian ini merupakan penelitian deskriptif kualitatif dengan melakukan analisis kebahasaan yang melibatkan konteks dan hal-hal lain di luar kebahasaan pada memoar berjudul Sarinah: Kewadjiban Wanita dalam Perdjoangan Republik Indonesia (1947) karya Ir. Soekarno. Memoar tersebut merupakan buku yang berisi pemikiran dan gagasan Soekarno tentang perempuan kaitannya dengan negara. 
Suyanto, Sosok Perempuan dalam Pandangan Bung Karno pada Memoar Sarinah : Sebuah Analisis Wacana Kritis

Data penelitian ini merupakan teks yang berfokus pada bahasa seksis yang digunakan penulis untuk menggambarkan perempuan dalam teks. Data dikumpulkan dengan metode simak, yaitu memperhatikan dengan seksama penggunaan bahasa dalam teks (Sudaryanto, 2015: 203).

Analisis data dilakukan dengan metode padan yang mengaitkan bahasa dengan faktor-faktor di luar kebahasaan yaitu konteks. Penelitian ini menggunakan model Miles \& Huberman (dalam Sugiyono, 2012) yang dilakukan melaui tiga tahap yaitu reduksi data, displai data, kesimpulan/verifikasi. Pertama tahap reduksi data, dalam tahap ini peneliti melakukan: (1) pemilahan data yang penting berdasarkan tujuan yang telah ditentukan, (2) membuat kategorisasi data, (3) membuat pola, dan (4) menyingkirkan data yang tidak relevan dengan tujuan penelitian yang telah ditentukan.

Tahap kedua yaitu displai data. Analisis yang dilakukan pada tahap ini adalah menyajikan kategorisasi ke dalam pola-pola tertentu. Tahap ketiga yaitu kesimpulan atau verifikasi yang dilakukan dengan cara memilih yang penting, menyimpulkan pengkategorisasian dan pemolaan yang telah dilakukan dan membuang hal-hal yang tidak dipakai atau diperlukan. Analisis dilanjutkan dengan menafsirkan dan memaknai kategorisasi dan pola yang sudah dibangun beradasarkan teori stilistika feminis (Mills, 1995).

\section{Hasil dan Pembahasan}

\section{Perempuan di Mata Soekarno}

Bagian ini merupakan pembahasan hasil dari penelusuran yang dilakukan untuk mengurai pandangan Soekarno tentang perempuan. Pandangan tersebut diselidiki melalui identitas sosial Soekarno selaku penulis buku Sarinah. Gambaran identitas sosial inilah yang bisa dijadikan sebagai salah satu penyebab paling esensial yang membentuk praktik seksisme dalam buku Sarinah.

Berdasarkan hasil penelusuran melalui beberapa biografi dan literatur yang membahas tentang perjalanan hidup Soekarno dan sepak terjangnya terhadap kepentingan perempuan. Berdasarkan penelusuran tersebut didapati bahwa ada beberapa nilai-nilai penting yang menjadi landasan Soekarno untuk memperhatikan nasib-nasib perempuan di negaranya. Nilai-nilai tersebut antara lain adalah sikap nasionalisme yang tinggi, nilai humanisme yang diperolehnya sejak kecil dan paham sosialisme yang telah dipelajarinya 
semasa muda. Ketiga nilai tersebut menjadi hal-hal fundamental yang sangat memengaruhi sikap politik Putra Sang Fajar tersebut.

Nilai pertama, yaitu nilai nasionalisme. Rasa nasionalisme yang ada pada jiwa Soekarno telah terbentuk sejak usianya masih sangat muda. Wisnuwardhana (2015: 49-51) menuturkan bahwa paham nasionalisme Soekarno terpupuk secara tidak langsung berdasarkan kisah-kisah patriotisme yang diceritakan oleh ibundanya, Idayu. Idayu kerap menghibur Soekarno kecil dengan kisah-kisah perlawanan yang dilakukan oleh buyutbuyutnya yang ternyata merupakan para pejuang. Buyut dari ibunya adalah seorang pejuang yang gugur dalam medan Perang Puputan yang melawan Belanda agar Raja Singaraja tetap utuh. Demikian pula dengan buyut dari kakeknya yang juga gugur dalam medan perang. Buyutnya merupakan patriot gagah berani, yang dikatakan sejajar dengan Pangeran Diponegoro dalam Perang Besar di Jawa sekitar tahun 1825-1830. Melalui kisahkisah tersebut, nilai patriotisme dan cinta tanah air menjadi pelajaran pertama yang diterima oleh Soekarno dari orang tuanya.

Selanjutnya, humanisme adalah nilai yang diperoleh Soekarno dari pengasuhnya, yang juga menjadi judul buku tentang perempuan yang dikarangnya, Sarinah. Soekarno akrab memanggilnya Mbok Sarinah, ia merupakan pembantu di rumahnya sekaligus pengasuh Soekarno yang dibayar dengan cuma-cuma. Menurut Adams (2014: 30-31) Soekarno mendapatkan nilai humanisme dari Sarinah melalui nasihat-nasihatnya tentang cinta kepada sesama terutama rakyat kecil.

Sementara itu, nilai-nilai sosialis diperoleh Soekarno tatkala dirinya menginjak usia belasan tahun. Saat itu Soekarno sedang menempuh pendidikan di HBS Surabaya dan dititipkan oleh kedua orang tuanya kepada H.O.S. Tjokroaminoto. Dialah yang memberi pengaruh besar pada perubahan cara berpikir Soekarno. Menurut Wisnuwardhana (2015: 59-63) dari Tjokroaminoto Soekarno banyak berkenalan dengan berbagai tokoh dunia dan para pemikir dari barat seperti Thomas Jefferson, George Washington, Karl Marx, Lenin, Voltaire, J.J.Rousseau, dan masih banyak lagi. Dari semua pemikiran-pemikiran dari barat tersebut, Soekarno berkenalan dengan paham sosialisme dan marxisme yang berorientasi pada keadilan dan rakyat golongan bawah (jelata).

Dari ketiga pengalaman-pengalaman tersebutlah muncul keinginan yang sangat besar dalam hati Soekarno untuk bisa mewujudkan nilai-nilai itu pada negerinya. Soekarno menginginkan negrinya bisa terbebas dari penjajahan dan imperialism dengan menegakkan 
rasa cinta tanah air dan sikap nasionalisme dari seluruh rakyatnya termasuk perempuan. Oleh karena itu, Soekarno berusaha untuk melibatkan perempuan dalam perjuangannya memajukan bangsa. Bagi Soekarno, hal ini juga menjadi salah satu praktik nilai humanisme dan sosialisme yang dimiliknya, yaitu perempuan bukan hanya mendapat kesetaraan gender dalam masyarakat tetapi juga kedudukan dan posisi penting dalam perjuangan. Dia mencintai para perempuan dan ingin menghormatinya sebagai salah satu bagian dari masyarakat tanpa membedakannya dengan laki-laki.

Oleh karena itu, bisa dikatakan penyebab yang paling mendasar atas penulisan buku berjudul Sarinah adalah rasa kecintaan Soekarno pada negaranya, Indonesia. Dia menginginkan nasib baik terjadi pada negaranya dengan cara melibatkan perempuan dalam gerakan politis. Maka hal tersebut menunjukan bahwa perhatian memajukan perempuan bagi Soekarno lebih terfokus pada keikutsertaan mereka (perempuan) pada kegiatan politis dalam memajukan bangsa. Menurutnya, dengan berjalannya hal tersebut bisa menempakan perempuan pada kedudukan yang lebih layak di masyarakat. Namun terbukti hingga saat ini, seksisme yang terjadi pada perempuan belum bisa diberantas jika hanya berfokus pada politisasi gerakan perempuan. Itu karena hal paling fundamental dalam menghapuskan seksisme pada perempuan adalah revolusi cara pandang dan perubahan konstruksi pada masyarakat.

Selanjutnya, penyebab kedua fenomena seksisme dalam buku Sarinah adalah sikap Soekarno yang dikatakan sebagai pengagum perempuan. Menurut Wisnuwardhana (2015: 47), Soekarno mengawini banyak perempuan karena ia mengagumi sifat-sifat mereka. Ia menganggap bahwa kecantikan perempuan adalah keindahan yang alami. Karena itu salah satu wujud kecintaanya adalah mengagumi lahiriah perempuan karena menurutnya mengagumi kecanikan perempuan bukanlah perbuatan jahat atau dosa. Berdasarkan hal tersebut, maka beberapa pemilihan kata pada buku Sarinah mungkin saja terpengaruh dengan rasa kekaguman Soekarno sehingga ada banyak teks yang memfragmentasikan bagian-bagian tubuh perempuan dan mereduksi perempuan bukan sebagai satu kesatuan dalam sebuah representasi yang sesuai sehingga membentuk praktik seksisme. Dalam hal ini perempuan masih diposisikan sebagai objek keindahan semata.

Penyebab ketiga terjadinya seksisme dalam buku Sarinah berkaitan dengan pemikiran Soekarno yang ingin tetap mempertahankan budaya patriarki agar laki-laki dan perempuan tetap pada kodrat alam namun dengan berlandaskan keadilan. Menurut 
Suyanto, Sosok Perempuan dalam Pandangan Bung Karno pada Memoar Sarinah : Sebuah Analisis Wacana Kritis

Wisnuwardhana (2015: 118) "Soekarno dengan tegas menyatakan ketidaksetujuannya terhadap pergerakan feminisme di Eropa sebab mereka menghendaki persamaan mutlak antara laki-laki dan perempuan". Hal ini bisa jadi dasar penyebab adanya praktik seksisme dalam bentuk penamaan dan androsentrisme yang terjadi pada teks yang terjadi tanpa disadari oleh penulisnya. Sebab, perempuan masih akan tetap dipandang sebagai sesuatu yang berbeda jika perspektif yang digunakan hanya dari laki-laki saja seperti yang dilakukan oleh Soekarno.

\section{Potret Sarinah, Perempuan pada Masa Kemerdekaan}

Bagian ini mengurai apa saja faktor sosiokultural yang membentuk seksisme pada buku Sarinah. Fakor sosiokultural tersebut ditelusuri melalui gambaran kehidupan perempuan dalam masyarakat serta konstruksi gender yang terjadi saat itu. Pertama, pada waktu itu telah terjadi adanya perubahan dalam pemaknaan budaya patriarki. Budaya patriarkat pada awalnya diterapkan agar peradaban jauh lebih maju di banding saat zaman matriarkat karena pada zaman itu hubungan antara laki-laki dan perempuan lebih tidak jelas. Kemudian, ketidakadilan muncul pada budaya patriarki selanjutnya, saat laki-laki memiliki hasrat untuk memenuhi keinginan dan hasrat untuk memiliki. Sejak saat itu, laki-laki mulai memperlakukan perempuan seperti manusia yang tidak berharga. Mereka merasa lebih berkuasa dan superior. Hal tersebut terus berjalan termasuk pada masa kemerdekaan. Perempuan ditempatkan pada posisi inferior yang segala nasibnya ditentukan oleh lakilaki. Laki-laki merasa memiliki hak untuk mengatur hidup perempuan sedangkan perempuan dituntut untuk menerima segala keputusan laki-laki.

Faktor sosiokultural yang kedua adalah peran perempuan yang diposisikan sebagai Konco Wingking dalam budaya patriarki Jawa. Hal ini karena penulis buku, Soekarno, menghabiskan hidup lebih banyak di pulau Jawa sehingga lebih akrab dengan budaya Jawa. Menurut Sahayu (2011: 193), terjemahan harfiah dari konco wingking adalah teman belakang. Konsep ini dalam isu kesetaraan gender merefleksikan adanya diskriminasi terhadap eksistensi perempuan karena dalam konsep ini laki-laki dianggap lebih layak menjadi pemimpin dan selalu dijadikan parameter dalam hubungan suami - istri. Oleh karena itu, konsep ini menggambarkan kepasifan perempuan karena tugasnya hanya pada urusan rumah tangga. Laki-laki tidak pernah melibatkan perempuan dalam urusan publik. Perempuan sebagai Konco wingking masih terjadi pada masa kemerdekaan termasuk saat Soekarno mulai memikirkan nasib perempuan. Meskipun konsep ini ditolak oleh Soekarno, 
namun seksisme dalam buku Sarinah membuktikan bahwa Soekarno masih dipengaruhi oleh konsep tersebut tanpa dia sadari yang terlihat dari pemakaian dan pemilihan elemen dalam teks.

Kemudian, di sisi lain perempuan juga menganggap konsep konco wingking sebagai kebiasaan yang wajar. Hal inilah yang menjadi faktor sosiokultural yang ketiga, yaitu ketidaksadaran kaum perempuan akan ketidakadilan yang mereka alami. Hanya ada segelintir perempuan saat itu yang sudah menyadari akan subordinasi yang dilakukan lakilaki. Menurut Soekarno, ada tingkatan-tingkatan dalam pergerakan perempuan berdasarkan kesadaran yang mereka miliki. Lebih lanjut, menurutnya saat itu perempuan Indonesia masih dalam tingkatan pertama, yaitu kesadaran dalam lingkup dan urusan rumah tangga yang masih terikat oleh kendali sistem patriarki. Sementara itu, Soekarno menghendaki kesadaran lain dari perempuan agar bisa menghasilkan pergerakan yang lebih maju dalam memerdekakan mereka dan membangun bangsa, yaitu melalui gerakan politik kaum perempuan.

Ketiga hal tersebutlah menjadi faktor sosiokultural yang membentuk dan mengkonstruksikan ketidakadilan gender dalam praktik seksisme pada buku Sarinah.

\section{Simpulan}

Ada tiga identitas sosial yang menyebabkan seksisme pada perempuan dalam buku Sarinah, pertama, Soekarno hanya fokus pada politisasi gerakan perempuan untuk mewujudkan gairah patriotismenya pada negara; kedua, Soekarno masih ingin mempertahankan budaya patriarki meskipun dengan berlandaskan rasa keadilan kepada sesama; ketiga, Soekarno memiliki rasa kekaguman yang besar pada keindahan dan kecantikan perempuan sehingga hal ini memengaruhi cara pandangnya terhadap perempuan.

Ada tiga faktor sosiokultural yang mengkonstruksikan gender pada masa buku tersebut diterbitkan yang dimungkinkan menjadi penyebab terjadinya seksisme pada buku Sarinah. Pertama, perasaan superioritas yang dimiliki laki-laki; kedua, peran perempuan seagai konco wingking; ketiga, kesadaran perempuan yang belum lahir terhadap ketidakadilan yang mereka alami.

\section{Daftar Pustaka}

Adams, Cindy. 2014. Bung Karno-Penyambung Lidah Rakyat Indonesia. Jakarta: Yayasan Bung Karno. 
Asmarani, Ratna. 2011. "Kompleks Cinderella pada Diri Lily Bart dalam Novel The House of Mirth, Karya Edith Wharton", Kajian Sastra. Vol.35/1,2011.

Badara, Aris. 2013. Analisis Wacana: Teori, Metode, dan Terapannya pada Analisis Wacana Media. Jakarta: Kencana.

Budiwati, Tri Rina dan I Dewa Putu Wijana. 2004. "Bias Gender dalam Bahasa Indonesia" dalam Humanika. Vol.XVII/2.

Bungin, Burhan. 2008. Sosiologi Komunikasi: Teks, Paradigma, dan Diskursus Teknologi Komunikasi di Masyarakat. Jakarta: Kencana.

Collins, Patricia Hill. 2012. "Social Inequality, Power, and Politics:Intersectionality and American Pragmatism in Dialogue". Journal of Speculative Philosophy, Vol. 26 (2).

Dick, Teun van. 2001. "Principles of Critical Discourse Analysis", dalam Discourse Theory and Practice. Margaret Wetherell et al. (eds). London: Sage Publication.

Jorgensen, Marianne W. dan Louise J Phillips. 2010.Analisis Wacana: Teori dan Metode. Ditejemahkan oleh Imam Suyitno, Lilik Wahyuni, dan Suwarna. Editor Abdul Sykur Ibrahim. Yogyakarta: Pustaka Pelajar.

Kesuma, Tri Mastoyo Jati. 2007. Pengantar Penelitian Bahasa. Yogyakarta: Carasvatibooks.

Langermann, Paricia Madoo and Jill Niebrugge. 1996. "Contemporary Feminist Theory", in George Ritzer, Modern Sociological Theory, $4^{\text {th }}$ ed. New York: The McGrawHill.

Mills, Sara. 1995. The Interface Series: Feminist Stylistics. London: Routledge.

Muzakka,Moh. 2010. "Perjuangan Perempuan Melawan Hegemoni Patriarki: Kajian terhadap Novel Perempuan Berkalung Sorban", Kajian Sastra, Vol.34/2, Hal. 128138.

Nurulhady, Eta Farmacelia. 2011. The Strugle of the Other: Maggie Tulliver in George Eliot's the Mill on the Floss" dalam Kajian Sastra, Vol.34/1, hal.69-81.

Ritzer, George. 1996. Modern Sociological Theory, $4^{\text {th }}$ (eds.). New York: The McGrawHill.

Tong, Rosemarie Putnam. 2010. Feminist Thought: Pengantar Paling Komprehensif kepada Arus Utama Pemikiran Feminis. Yogyakarta: Jalasutra.

Sahayu, Wening. 2011. "Adjective Check List Pengungkap Stereotip Laki-laki dan Perempuan Menurut Persepsi Mahasiswa dari Sepuluh Etnis". Litera, vol 10, 2.

Sudaryanto. 2015. Metode dan Aneka Teknik Analisis BahasaPengantar Penelitian Wahana Kebudayaan secara Linguistis. Yogyakarta: Sanata Dharma University Press.

Sugiyono. 2012. Metode Penelitian Bisnis. Bandung: Alfabeta.

Sunardi. 2007. Diferensiasi Linguistis Berdasarkan Gender dalam Teks Sastra Inggris, dalam Linguistisa. Vol.14/27. 
Sungkar, Lubna. 2011. "Citra Perempuan dalam Clochette dan Madame Baptise Karya Guy de Maupassant", Kajian Sastra. Vol.34/1, hal.82-94.

Titscher, Stefan et al. 2009. Metode Analisis Teks dan Wacana. Penerjemah Ghazali dkk. Editor Abdul Sykur Ibrahim. Yogyakarta: Pustaka Pelajar.

Wirjosutedjo, MN dan Rachmat Djoko P. 2004. "Marjinalisasi Perempuan dalam Bekisar Merah dan Belantik Karya Ahmad Tohari: Tinjauan Kritik Sastra Feminis". Humanika, Vol.17/No.3 (Juli).

Wisnuwardhana, S. 2015. Sarinah: Mata Air Cinta, Humanisme, dan Fmnisme Soekarno dalam Pelukan Cinta Sang Ibu Asuh. Yogyakarta: PALAPA.

\section{Sumber Data}

Soekarno. 1947. Sarinah: Kewajiban Wanita dalam Perjoangan Republik Indonesia. Yogyakarta: The Soekarno Foundation. 